\title{
Bending reinforcement of timber beams with composite carbon fiber and basalt fiber materials
}

\author{
Pilar de la Rosa García ${ }^{a, *}$, Alfonso Cobo Escamilla ${ }^{\text {b }}$, M. Nieves González García ${ }^{a}$ \\ ${ }^{a}$ Architectural Construction Department, School of Building Engineering, Polytechnic University of Madrid, Juan de Herrera Street, 6, 28040 Madrid, Spain \\ ${ }^{\mathrm{b}}$ Edification Technology Department, School of Building Engineering, Polytechnic University of Madrid, Juan de Herrera Street, 6, 28040 Madrid, Spain
}

\section{A B S T R A C T}

This work shows a study based on data obtained experimentally using bending tests of pine timber beams reinforced with composite materials. Fibers used for the execution of the reinforcement are basalt and carbon. Basalt fiber composites are applied in different grammages, whereas with carbon composites, unidirectional and

bidirectional fabrics are used. The behavior of the beams was analyzed regarding the reinforcement variables applied, and the results are compared with those of the tested beams without reinforcement. This work proves the good behavior of fiber reinforce plastic (FRP) with basalt fiber when applied to timber beams, and that of
Bidirectional carbon fabrics as opposed to the unidirectional ones.

Keywords:

A. Polymer matrix composites (PMCs

A. Wood (pinus sylvestris)

B. Fracture

D. Mechanical testing

\section{Introduction}

Many of the buildings of the built heritage include a structure composed by timber elements. The economic volume involved in the maintenance and renewal of this built heritage is considerable, therefore, the study of the different reinforcement techniques applicable to this type of structure is of special interest. The wooden structures have traditionally been reinforced either with steel or with pieces of the same material, increasing the section of the damaged parts [1]. The emergence of polymer composites reinforced with fibers, and their progressive use in construction, started to be applied as reinforcement in timber structures at the beginning of the nineties decade in the 20th century (Sins Bridge, 1992).

Wood is a natural material with an excellent ratio between its mechanic characteristics and its weight. This feature is maintained with the use of composites as reinforcement. In terms of its constitutive model, linear elastic behavior parallel to the fiber up to fracture is admitted when subjected to tensile stress, while under compression, an initial linear elastic behavior, followed by a section plasticizing, is considered[2]. In sawn timber beams subjected to bending, the predominant failure is mainly due to tensile stress; and frequently the fracture is located at the beam lower face. The FRP have a linear elastic behavior until fracture occurs, and have excellent mechanical properties in relation to their weight and

\footnotetext{
* Corresponding author. Tel.: +34 687246944 .

E-mail addresses: pilar.delarosa@upm.es (P. de la Rosa García), alfonso.cobo@upm.es (A.C. Escamilla), mariadelasnieves.gonzalez@upm.es (M. Nieves González García).
}

volume. If the beam is reinforced by its lower face, its capacity to absorb tensile stresses will increase, and therefore, an increase in its carrying capacity is likely to be produced, as well as an increase in ductility.

This paper analyzes the benefits different reinforcement systems of U-shaped composite materials provide, with the aim of contributing to the knowledge of this technique for recovering or increasing the strength properties of timber elements subjected to bending loads.

The first research works found in the revised literature devoted to the study of the behavior of FRP-reinforced wooden elements appeared in the sixties $[3,4]$. These research studies used glass fiber composites to reinforce solid wooden beams. In 1981 Spaun [5] studied the stiffness and tensile strength increase in reinforced beams tested to bending, using in this case, also the glassfiber reinforcement. Subsequently, the carbon fiber started to be applied as reinforcement material in wooden beams [6,7]. In the work by Triantafillou and Plavris [6] the reinforcement applied was in the form of sheet without prestressing, while a later work by Triantafillou and Deskivic [7] studied the behavior of reinforcements by applying the same sheets but previously prestressed. An increase in the carrying capacity of beams was observed regarding the beams reinforced with non-prestressed sheets. Prestressed sheets were also under study in the works published later $[8,9]$. In such works, a theoretical analysis of the carrying capacity increase in reinforced beams with prestressed sheets is presented and compared to the non-prestressed sheet reinforcement. In addition, it is experimentally tested confirming what was predicted by the theoretical model. 
The proper functioning of the surface bonding between the wood and the reinforcement is essential for the correct response of the reinforced set. This aspect has also been studied on several occasions [10,11]. In 1999 Dagher [12] announced it was possible to increase bending strength up to $100 \%$ by reinforcing beams only at their lower face. The increase depends on the proportion of reinforcement applied on the section. However, this increase is not proportional to the percentage of reinforcement applied, since failure occurs at the interface between reinforcement and timber before the reinforcement coming to depletion produces fracture by shear. This suggests that bending failure of beams varies depending on the characteristics of reinforcement [13]. The previous characteristics of reinforced beams are also determining. The existence of splits can cause premature failure by shear. Several authors have analyzed and proposed reinforcement shear sheets arranged lengthwise at the transverse side faces [14,15]. Another form of shear reinforcement is carried out with FRP pultruded rods embedded with epoxy resin into holes in the lower side [16].

Fibers used as reinforcement in composite materials have been, in most part of the research undertaken to date, glass and carbon. In the first published works of reinforced wooden elements, mainly those made with glass fiber were studied [17-20]. Later, carbon fiber was introduced in the market, and the number of research works using carbon fiber applied as reinforcement in this type of elements increased [21,22]. There are also works, although in fewer numbers, in which the employed fibers are aramid [23]. Studies of basalt used as composite reinforcement fiber are scarce [24], and even more so when the material to be reinforced is wood. Quanfeng, in his study of 2010 [25] concludes that FRP reinforcements improve the mechanical properties of reinforced wooden elements and that the simulation of their performance by means of the finite element method is reliable. As for verifying the reliability of the design models to predict the bearing capacity of the reinforced elements, several works have also been published treating this matter $[8,26,27]$, using the transformed section method and the section conditions of equilibrium. The authors checked the setting of these methods with the results obtained experimentally [9]. When applying calculation models, an elastic plastic behavior of wood when under compression is considered, as well as a linear elastic behavior of wood in tension, and that of the reinforcement in tension up to fracture. In addition, beams of laminated wood have also been reinforced with FRP in several research studies with good results [28-30].

The increase of the carrying capacity of reinforced beams varies mainly according to the nature of the element to be strengthened, the type of fiber used, the layout of the reinforcement in the element, the volume of FRP and the integrity of the bonding surface between FRP and timber during all the test until fracture occurs. Therefore, results obtained in research works carried out vary depending on the aforementioned aspects. Some of the published conclusions are that the carrying capacity of beams reinforced with unidirectional carbon fiber reinforced plastic (CFRP) can increase between $20 \%$ and $40 \%$ when compared to the non reinforced ones [7]. In the study by Tingley and Kent, 2001 [31] where beams reinforced with CFRP were also tested, an increase in carrying capacity of $21.5 \%$ and $5 \%$ in stiffness were obtained. Fiorelli and Alves [32] indicate in their work that the increase in stiffness of beams reinforced with glass fiber reinforced plastic (GFRP) was between 15\% and $30 \%$. In the work presented in 2010 by Yusof and Saleh [33] beams were reinforced with GFRP rods embedded in slots at the lower side. The tested carrying capacity increase in this case was between $20 \%$ and $30 \%$, and the stiffness increase in between $24 \%$ and $60 \%$.

As can be seen, results vary among the different cases, and this is due to the use of different types of reinforcement, as well as to the characteristics of the timber used.

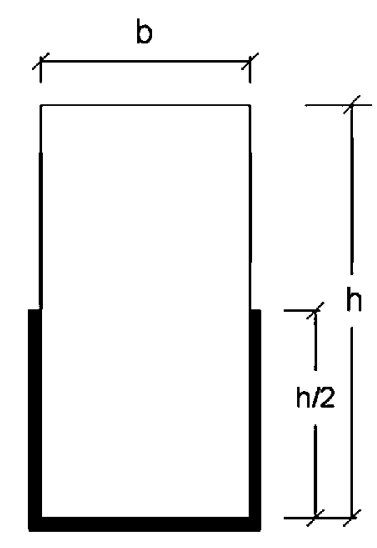

Fig. 1. Distribution of the reinforcement.

In this article, several types of reinforcement are analyzed in order to contribute to the knowledge of the FRP reinforcement of timber structures, and thereby optimizing its use.

\section{Materials and research methodology}

Tests were conducted with beams and "U" distribution reinforcements as shown in Fig. 1. A universal testing machine was used. The stress increase applied was performed at a speed of $1 \mathrm{KN} / \mathrm{sg}$. The test was conducted with a single point of load application, being the span between supports of $1 \mathrm{~m}$. The load was applied at $500 \mathrm{~mm}$ of the supports, i.e. at the midpoint of the span (Fig. 2). Twenty-six beams were tested, of which nine were tested without strengthening and 17 reinforced.

\subsection{Timber mechanical properties}

Timber is from pinus sylvestris from Valsaín area, $78 \times 155 \mathrm{~mm}$ of section and length $1090 \mathrm{~mm}$. All beams, before being reinforced, were classified according to the UNE 56544 standard, regarding visual classification of timber for structural use (conifer wood). This standard is set for the case of the beams under study, where the beam depth is less than $70 \mathrm{~mm}$, a single quality class, MEG, which corresponds, in the case of the pinus sylvestris to resistant class C18. Mechanical properties for each strength class are set in the UNE-EN 338 standard. The beams, which were outside the limits set by the standard - due to their singularities or presence of defects - were classified as rejected, and no mechanical properties were established for them within this standard. From the 26 tested beams, 12 were classified as $\mathrm{C} 18$ and 14 as rejected. Beams were distributed evenly for each type of reinforcement, i.e. the same number of beams $\mathrm{C} 18$ and $\mathrm{R}$ for each reinforcement system and beams without reinforcement.

\subsection{Reinforcing material}

Reinforcements were performed on site in the lab with different types of fibers. Beams tested without reinforcement were nine, the others were reinforced with different systems and different types of fiber fabrics whose characteristics are shown in Table 1. From the 17 reinforced beams, three were reinforced with unidirectional basalt fibers and $280 \mathrm{~g} / \mathrm{m}^{2}$ grammage (FB280 ${ }^{1}$ ), the other three beams were reinforced with the same basalt fiber, but with a grammage greater than $600 \mathrm{~g} / \mathrm{m}^{2}\left(\mathrm{FB} 600^{2}\right)$. Both fibers were combined with an epoxy resin matrix to form the composite material. The other beams were reinforced with carbon fiber with the following

${ }^{1}$ Unidirectional basalt fibers of $280 \mathrm{~g} / \mathrm{m}^{2}$ grammage reinforcement

${ }^{2}$ Unidirectional basalt fibers of $600 \mathrm{~g} / \mathrm{m}^{2}$ grammage reinforcement. 


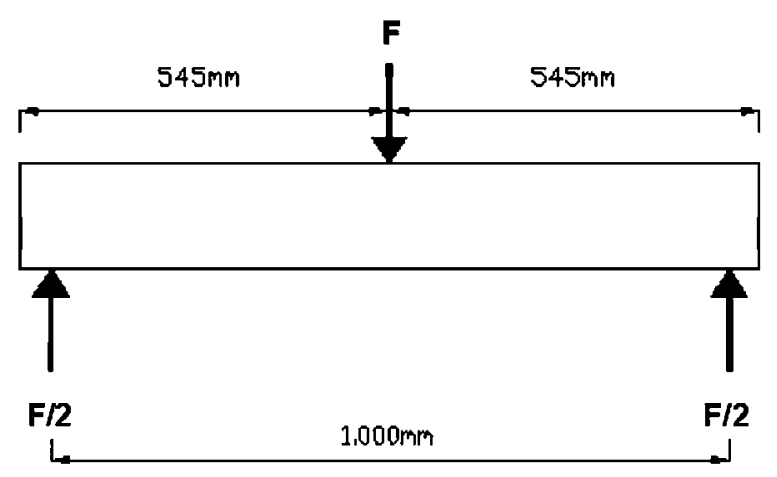

Fig. 2. Diagram of the tests.

characteristics: three of them with unidirectional $300 \mathrm{~g} / \mathrm{m}^{2}\left(\mathrm{FC} 300^{3}\right)$ and epoxy resin, four with bi-directional fiber of $160 \mathrm{~g} / \mathrm{m}^{2}$ $\left(\right.$ FC160\# $\left.1^{4}\right)$ and four with bi-directional fiber of $210 \mathrm{~g} / \mathrm{m}^{2}$ $\left(F C 210 \# 1^{5}\right)$. Of these eight last beams, half of them were reinforced with a single layer of fiber (FC160\#1 and $\mathrm{FC} 210 \# 1$ ) and the other half with a double layer ( $\mathrm{FC} 160 \# 2^{6}$ and $\mathrm{FC} 210 \# 2^{7}$ ). Composite materials were manufactured in situ. The reinforcement distribution remained the same in all cases, in " $U$ " shape, applying the reinforcement in the lower face and side faces up to approximately half of the height. Prior to applying the first coat of resin, the wood surface was cleaned with a brush, and a primer layer (XPS 400S) was applied to improve the adherence between the composite and wood. After the primer, initial resin layer was applied with an approximate efficiency of $0.5 \mathrm{~kg} / \mathrm{m}^{2}$. Then unidirectional fabric was applied parallel to the longitudinal direction of the beam and finally a finishing coat was applied with an approximate efficiency of $0.3 \mathrm{~kg} / \mathrm{m}^{2}$. This system was the one used for unidirectional fabrics: FB280, FB600 and FC300. Systems with bi-directional fabrics, FC160\# and FC210\# were following a similar process, in which the matrix of the composite material was epoxy mortar instead of resin. In this case the surface of the beams was also cleaned and a previous primer was applied. Bi-directional fabrics were placed in one and in two layers. The performance of the epoxy mortar in the initial layer was $0.8 \mathrm{~kg} / \mathrm{m}^{2}$ and in the intermediate one when applied, and the completion one of $0.6 \mathrm{~kg} / \mathrm{m}^{2}$ approximately. Fig. 3 shows the image of three beams reinforced with FB280 and resin epoxy.

\section{Experimental results}

The data obtained were supplied by the software associated to the testing equipment. The results correspond to the loads applied and to the vertical displacements experienced by the beams where the load is applied, up to fracture. With this data, load/displacement graphs for each of the beams were obtained. The most common failure mode was the fracture of the lower fibers corresponding to the tensile zone, both in reinforced and non-reinforced beams.

In the case of reinforced beams, reinforcement fibers fracture was also produced, which indicates that delamination did not exist, and that the bonding surface maintained its integrity until the end of the test. Only in two cases reinforcement fracture was not appreciated, indicating that detachment occurred during the test, breaking only the wood fibers. From the 27 beams tested, only

\footnotetext{
${ }^{3}$ Unidirectional carbon fibers of $300 \mathrm{~g} / \mathrm{m}^{2}$ grammage reinforcement.

${ }^{4}$ Bi-directional carbon fiber of $160 \mathrm{~g} / \mathrm{m}^{2}$ grammage reinforcement with a single layer.

${ }^{5} \mathrm{Bi}$-directional carbon fiber of $210 \mathrm{~g} / \mathrm{m}^{2}$ grammage reinforcement with a single layer.

${ }^{6}$ Bi-directional carbon fiber of $160 \mathrm{~g} / \mathrm{m}^{2}$ grammage reinforcement with a double layer.

7 Bi-directional carbon fiber of $210 \mathrm{~g} / \mathrm{m}^{2}$ grammage reinforcement with a double layer.
}

four fractured due to shear only, three of which were non-reinforced. Fig. 4 presents graphs of the fracture modes that occurred in the tested beams. Only one beam failed to compression (Fig. 4, 2nd drawing). $77 \%$ of the beams fractured due to a failure of the lower fibers when in tension, or due to a combination of tension and shear (beams 1,3,4 and 7). In the failure mode 7, although fracture was not appreciated, the lower reinforcement timber fibers broke, experiencing previously a debonding of the reinforcement, and hence it is also failure to tension loads.

Table 2 lists the characteristics and the failure mode of each beam. Usually, tensioned fibers fracture occurred in the center of the span, moving laterally if significant knots exist in the area of greater bending moment, or due to the existence of an excessive inclination of fibers (less frequent case). In cases in which the fracture begins with shear close to the support, it usually coincides with the existence of considerable dimensions drying splits (Fig. 5).

\subsection{Beams reinforced with unidirectional basalt fiber fabric of $280 \mathrm{~g} /$ $\mathrm{m} 2$ and $600 \mathrm{~g} / \mathrm{m} 2$}

Fig. 6 shows the graphs of the six beams reinforced with unidirectional basalt fiber. As can be observed, the parts reinforced with reinforcement type FB280 fractured to a load greater than the FB600 type did, except for one of them, which failed by shear and obtained the lowest fracture load value of the six. In Table 3, the mean values of the ultimate fracture stress of the six beams are represented. The variation coefficient of the first ones is greater than the second ones, since the beam fracturing to shear does so in a load significantly smaller than the other two. In the case of the FB280, from the three beams tested, two fractured under a similar maximum load, something more $63 \mathrm{kN}$ and the failure occurred to tensile stress. In one of them, fiber fracture was not appreciated, and therefore, the debonding of the reinforcement occurred, however not a significant decrease was observed in the fracture load. The third beam failed to shear and a considerable drop in the mean fracture load was produced. This beam had significant drying splits, which was decisive in the failure mode and the value of the fracture load.

Reinforced beams with FB600 fabric had more homogeneous results. One of them failed to compression, and the other two to tension. In the one which failed to tension, fracture of reinforcement was not appreciated, and therefore, detachment of the timber composite material at the last moment of the test should have occurred. As happened previously with one of beams reinforced with FB280, the value of the fracture load did not vary greatly either.

\subsection{Beams reinforced with unidirectional carbon fiber fabric of $300 \mathrm{~g} /$ $\mathrm{m} 2$ and bidirectional carbon fiber of $160 \mathrm{~g} / \mathrm{m}^{2}$ and $210 \mathrm{~g} / \mathrm{m}^{2}$}

In the graph (Fig. 7), the load/displacement curves of each of the tested beams can be observed. The beams with unidirectional reinforcement FC300 and epoxy resin matrix were three, and the reinforced with bi-directional carbon fiber and epoxy mortar matrix were eight: two reinforced with FC160\#1 in one layer, two with the same reinforcement but in two layers (FC160\#2), and the other four reinforced with $\mathrm{FC} 210 \#$, also in one or two layers. Comparing the diagrams obtained, it can be seen that the highest fracture load values correspond to the beams reinforced with FC160\#. The reinforced with FC300 and FC210\# show similar results in terms of fracture load, although greater stiffness can be seen in the ones reinforced with FC260\#. In this case all beams experienced failure to tension or to tension combined with shear failure, except in one of the beams reinforced with FB160\#1, in which the failure occurred only by shear, although that does not imply a decrease in the mean. One of the three beams reinforced with FC300 failed to tension and shear, and in this case a drop in the value of the fracture stress was experienced, directly influencing the mean value. 
Table 1

Geometric and mechanical characteristics of the fabrics.

\begin{tabular}{lllll}
\hline Characteristics & FB280 & FB600 & FC300 & FC160\# \\
\hline Fiber & Basalt & Basalt & Carbon & Carbon \\
Fiber distribution & Unidirectional & Unidirectional & Unidirectional & Bidirectional \\
Gramaje $\left(\mathrm{g} / \mathrm{m}^{2}\right)$ & 280 & 600 & 300 & 160 \\
Thickness $(\mathrm{mm})$ & 0.103 & 0.222 & 0.167 & 0.040 \\
Tensile strength $(\mathrm{MPa})$ & 4000 & & 4900 & 210 \\
Elasticity modulus $(\mathrm{Mpa})$ & 84,000 & & 230,000 \\
\hline
\end{tabular}

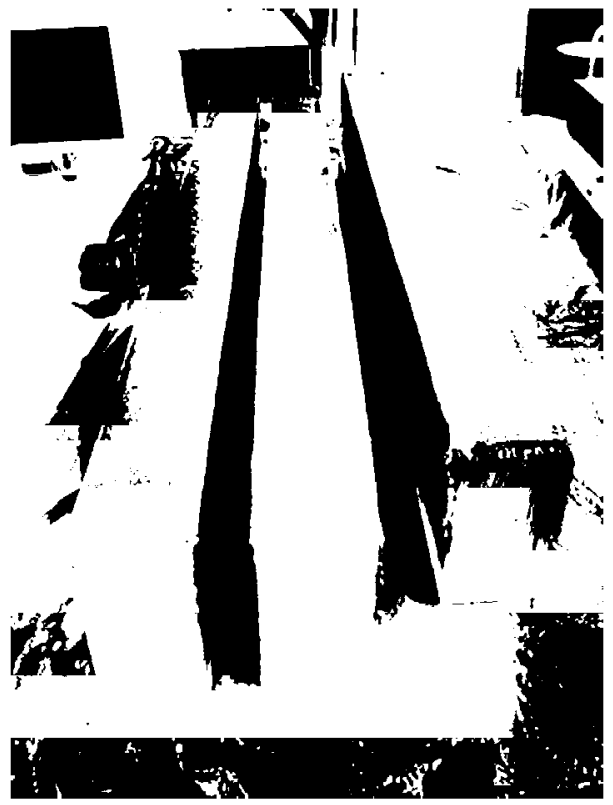

Fig. 3. Reinforced beams.

Anyway, the proper functioning of the FC160\# reinforcement can be noted. Table 4 shows mean values of fracture load, standard deviations and the variation coefficients for each reinforcement system.

\subsection{Beams without reinforcement, beams reinforced with carbon fiber} and with fabric of basalt fiber

In this section the results of all the beams tested will be analyzed, including the nine beams without reinforcement. Fig. 8 shows the load/displacement graphs of all the beams. It stipulates a stiffness increase in the case of reinforced beams, whichever reinforcement used.

In Table 5 the mean values of fracture load, standard deviations, and variation coefficients can be observed. From the data shown in this table, it can be extracted that the beams that have shown better results in terms of bearing capacity are the ones reinforced with carbon fiber bi-directional fabric of $160 \mathrm{~g} / \mathrm{m}^{2}$, obtaining virtually the same result by applying one or two layers.

The reinforcement system made with unidirectional basalt fiber has given good results with two grammage FB280 and FB600 applied.

\section{Analytical study}

\subsection{Specimens without reinforcement}

Six prismatic specimens, $158 \times 158 \times 300 \mathrm{~mm}$ made of wood with identical characteristics to the beams in terms of timber origin, quality, drying time and moisture content were tested. In this case, loads and displacements were obtained and with this information, the corresponding stress/strain diagrams were traced.

Following the generally admitted established model [2], the value of the elasticity modulus will be considered the same under tension and compression (Fig. 9). The behavior when subjected to compression is elastic plastic, and when subjected to tension, it is elastic, keeping the same slope in both elastic stretch of the diagram. This model largely coincides with the stress/strain diagrams obtained in the tests to compression of the prismatic specimens (Fig. 10). With these tests the elasticity modulus has been determined experimentally, and the mean value is $4999 \mathrm{~N} / \mathrm{mm}^{2}$. The resulting maximum compression stress $\sigma_{w c}$, is $23.73 \mathrm{~N} / \mathrm{mm}^{2}$. To obtain the tensile stress in the tested beams without reinforcement, a compression elastoplastic behavior model and tensile linear elastic one has been performed (Fig. 9). Using the data of the geometry of the tested beams, the maximum moment reached by the beam, the compressive strength and elasticity modulus of timber, wood tensile stress has been obtained. For the analysis,

1. Tensile

2. Compression
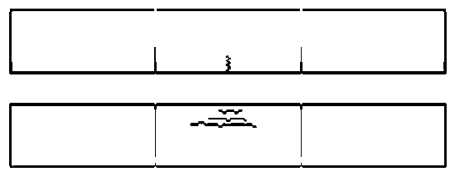

3. Tensile

4. Tensile and

Shear
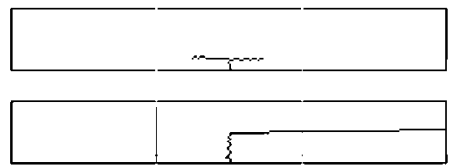

5. Shear

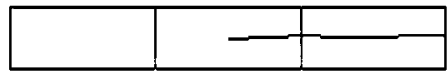

6. Shear
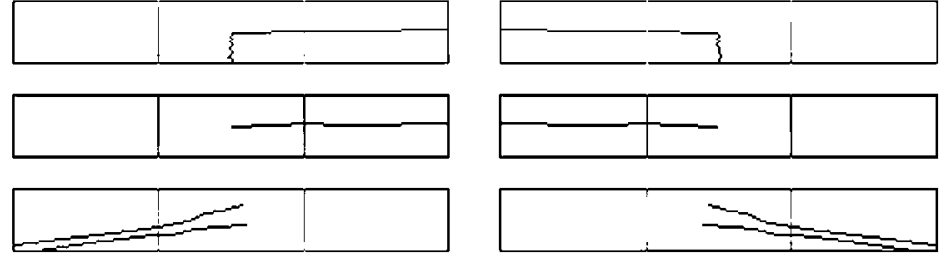

7. No visible fracture

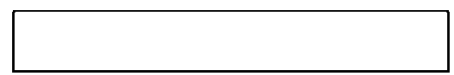

Fig. 4. Failure mode of tested beams. 
Table 2

Failure mode of tested beams.

\begin{tabular}{|c|c|c|c|c|c|c|c|c|c|}
\hline $\begin{array}{l}\text { Failure } \\
\text { mode }\end{array}$ & $\begin{array}{l}\text { Lower fibers } \\
\text { tensile stress }\end{array}$ & $\begin{array}{l}\text { Upper fiber } \\
\text { compression }\end{array}$ & Shear & $\begin{array}{l}\text { Span } \\
\text { center }\end{array}$ & $\begin{array}{l}\text { Influence of } \\
\text { drying splits }\end{array}$ & $\begin{array}{l}\text { Influence of fiber } \\
\text { inclination }\end{array}$ & $\begin{array}{l}\text { Influence of } \\
\text { nodes }\end{array}$ & $\begin{array}{l}\text { Reinforcement } \\
\text { detachment }\end{array}$ & $\begin{array}{l}\text { Failure } \\
\text { scheme }\end{array}$ \\
\hline 3SRC & $\mathrm{x}$ & & & $\mathrm{x}$ & & & & & 3 \\
\hline 7SRC & $x$ & & & $x$ & & & $x$ & & 3 \\
\hline $17 \mathrm{SRC}$ & $\mathrm{x}$ & & & $\mathrm{x}$ & & & & & 1 \\
\hline $27 \mathrm{SRC}$ & $\mathrm{x}$ & & $\mathrm{X}$ & & & $\mathrm{x}$ & $\mathrm{x}$ & & 1 \\
\hline 28SRC & $\mathrm{x}$ & & & $\mathrm{x}$ & & & & & 3 \\
\hline $32 S R C$ & & & $\mathrm{X}$ & & & & & & 6 \\
\hline 45SRC & & & $\mathrm{X}$ & & $\mathrm{x}$ & & & & 5 \\
\hline 97SRC & $\mathrm{x}$ & & $\mathrm{X}$ & & & & & & 4 \\
\hline 93SRC & $\mathrm{x}$ & & & $\mathrm{x}$ & & & & & 1 \\
\hline $56 \mathrm{FC} 300$ & $\mathrm{x}$ & & & & & & $\mathrm{x}$ & & 3 \\
\hline $69 \mathrm{FC} 300$ & $\mathrm{x}$ & & $X$ & & $\mathrm{x}$ & & & & 4 \\
\hline $72 \mathrm{FC} 300$ & $\mathrm{x}$ & & & $\mathrm{x}$ & & & $\mathrm{x}$ & & 1 \\
\hline $34 \mathrm{FB} 280$ & $\mathrm{x}$ & & & $\mathrm{x}$ & & & & $x$ & 7 \\
\hline $63 \mathrm{FB} 280$ & & & $\mathrm{X}$ & & $\mathrm{x}$ & & & & 5 \\
\hline $65 \mathrm{FB} 280$ & $x$ & & & & & & $x$ & & 3 \\
\hline $40 \mathrm{FB} 600$ & $\mathrm{x}$ & & & & & & $x$ & & 1 \\
\hline $60 \mathrm{FB} 600$ & $\mathrm{x}$ & & & & & & & $x$ & 7 \\
\hline 73 FB600 & & $\mathrm{x}$ & & $\mathrm{x}$ & & & & & 2 \\
\hline $89 \mathrm{FC} 160 \# 1$ & & & $\mathrm{X}$ & & $x$ & & & & 5 \\
\hline $48 \mathrm{FC} 160 \# 1$ & $\mathrm{x}$ & & $\mathrm{X}$ & & & $\mathrm{x}$ & $\mathrm{x}$ & & 4 \\
\hline $15 \mathrm{FC} 160 \# 2$ & $\mathrm{x}$ & & & $\mathrm{x}$ & & & & & 1 \\
\hline $22 \mathrm{FC} 160 \# 2$ & $\mathrm{x}$ & & & & & & & & 1 \\
\hline $8 F C 210 \mathrm{C} \# 1$ & $\mathrm{x}$ & & & $\mathrm{x}$ & & & & & 1 \\
\hline 13FC210\#1 & $\mathrm{x}$ & & & $\mathrm{x}$ & & & $\mathrm{x}$ & & 1 \\
\hline 23FC210\#2 & $\mathrm{x}$ & & & $\mathrm{x}$ & & & & & 3 \\
\hline $83 F C 210 \# 2$ & $\mathrm{x}$ & & $\mathrm{X}$ & & & & $\mathrm{x}$ & & 4 \\
\hline
\end{tabular}

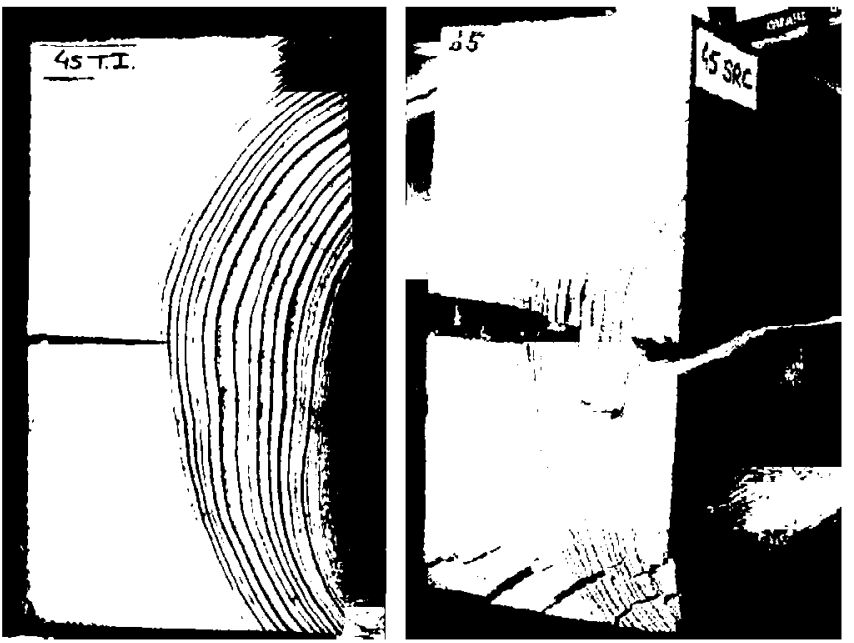

Fig. 5. Beam 45 , before and after the test.
Table 3

Mean fracture load values of beams reinforced with basalt fibers.

\begin{tabular}{llll}
\hline Beams & $\begin{array}{l}\text { Mean ultimate } \\
\text { fracture load }(\mathrm{kN})\end{array}$ & $\begin{array}{l}\text { Standard } \\
\text { deviation }\end{array}$ & $\begin{array}{l}\text { Variation } \\
\text { coefficient }(\%)\end{array}$ \\
\hline FB 280 & 58.55 & 7.30 & 12.47 \\
FB 600 & 54.04 & 1.19 & 2.20 \\
\hline
\end{tabular}

equilibrium equations (Eqs. (1) and (2)), preservation of plain sections (Eq. (3)) and constitutive laws of material (Eqs. (4)-(6)) have been used.

Equilibrium equations:

$$
\begin{aligned}
\sum F= & 0: \sigma_{w c} \cdot b \cdot y_{c 1}+\frac{1}{2} \cdot \sigma_{w c} \cdot b \cdot y_{c 2}-\frac{1}{2} \cdot \sigma_{w t} \cdot b \cdot y_{t}=0 \\
\sum M= & 0: \sigma_{w c} \cdot b \cdot y_{c 1} \cdot\left(y_{c 2}+\frac{y_{c 1}}{2}\right)+\frac{1}{2} \cdot \sigma_{w c} \cdot b \cdot y_{c 2} \cdot\left(\frac{2}{3} \cdot y_{c 2}\right) \\
& +\frac{1}{2} \cdot \sigma_{w t} \cdot b \cdot y_{t} \cdot\left(\frac{2}{3} \cdot y_{t}\right)=M_{u}
\end{aligned}
$$

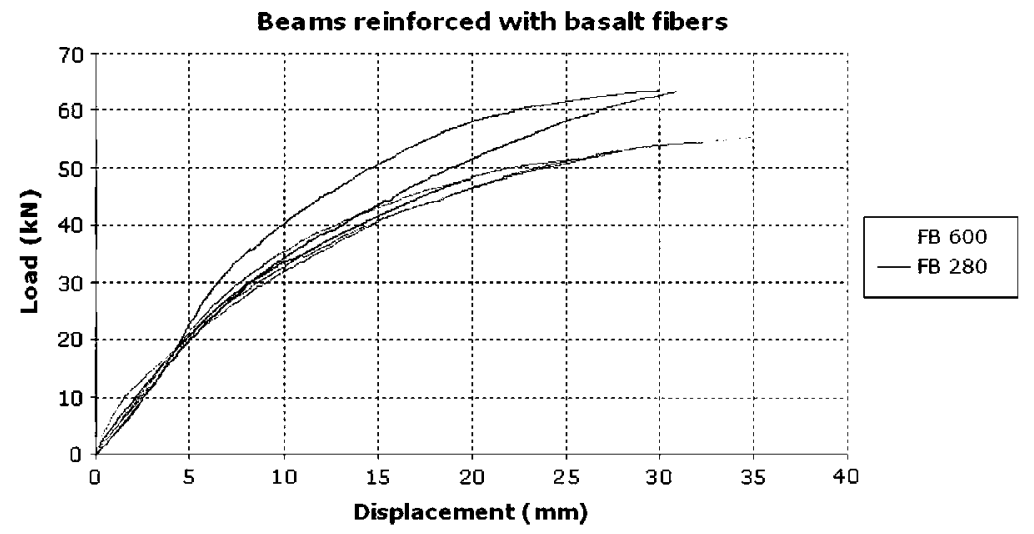

Fig. 6. Load/displacement graph of beams reinforced with basalt fibers. 


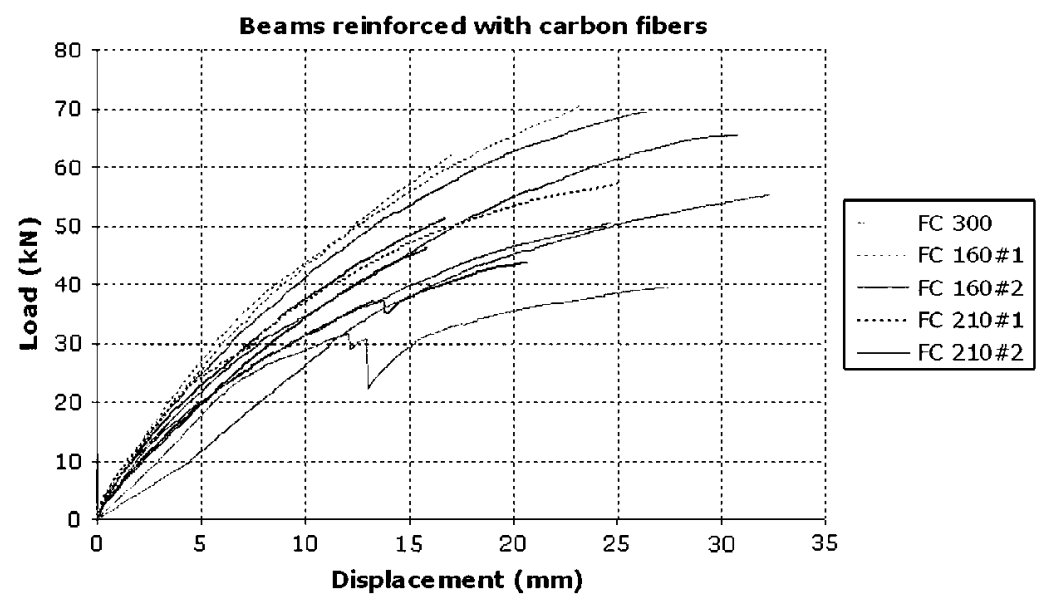

Fig. 7. Stress/displacement graph of beams reinforced with carbon fibers.

Table 4

Mean fracture load values of beams reinforced with carbon fibers.

\begin{tabular}{lllc}
\hline Beams & Ultimate load $(\mathrm{kN})$ & Sandard deviation & Variation coefficient (\%) \\
\hline FC 300 & 48.64 & 6.61 & 13.59 \\
FC 160\#1 & 66.35 & 4.07 & 6.13 \\
FC 160\#2 & 67.45 & 1.97 & 2.92 \\
FC 210\#1 & 51.73 & 5.42 & 10.48 \\
FC 210\#2 & 47.54 & 3.00 & 6.31 \\
\hline
\end{tabular}

Plain sections:

$\frac{\varepsilon_{c 1}}{y_{c 2}}=\frac{\varepsilon_{t}}{y_{t}}$

Constitutive law:

$\sigma_{w c}^{\prime}=E_{w} \cdot \varepsilon_{w}^{\prime} \rightarrow\left(0 \leqslant \varepsilon_{w}^{\prime} \leqslant \varepsilon_{c 1}\right)$

$\sigma_{w c}^{\prime}=\sigma_{w c} \rightarrow\left(\varepsilon_{c 1}<\varepsilon_{w}^{\prime} \leqslant \varepsilon_{c}\right)$

$\sigma_{w t}^{\prime}=E_{w} \cdot \varepsilon_{w}^{\prime} \rightarrow\left(0 \leqslant \varepsilon_{w}^{\prime} \leqslant \varepsilon_{t}\right)$

where $\sigma_{w c}$ is the maximum wood compression stress; $\sigma_{w t}$ is the maximum wood tensile stress, $M_{u}$ is the ultimate bending moment; $\varepsilon_{c}$ and $\varepsilon_{t}$ are the maximum strains in compression and tension respectively; $\sigma^{\prime}$ and $\varepsilon^{\prime}$ are values of stress and strain at any section point, $b$ is the section width; $\varepsilon_{c 1}$ is the elastic limit compression strain; $y_{t}, y_{c 1}$ and $y_{c 2}$, indicate the height of the neutral axis, the height of the plastic area and the height of the elastic area, respectively.

In Fig. 11, resulting forces corresponding to the compression region $\left(F_{w c 1}\right.$ and $\left.F_{w c 2}\right)$ and the tension zone $\left(F_{w t}\right)$ are also included. Using the previous equations, the wood tensile stress is obtained, $\sigma_{w t}$ de $42.40 \mathrm{~N} / \mathrm{mm}^{2}$.

Once the reinforcements were applied, the most common failure mode is still tensile stress; the composite material produces an increase in strength in the lower fibers, and stiffness of the specimens. Therefore, the plastic state fibers in the compression area will have a greater volume than in the non-reinforced beams, but without reaching total plasticizing and failure to compression.

\subsection{Reinforced specimens}

In this section the theoretical fractured load of reinforced beams, is calculated from mean values of the Young modulus $\left(E_{\mathrm{w}}\right)$ and maximum stress $\left(\sigma_{w c}\right.$ and $\left.\sigma_{w t}\right)$ of the wood obtained in testing as indicated in the Section 4.1. Also, using the real values of fracture load of each element, the maximum stress reached by the reinforcements is calculated.

The analysis model is based on the previously used model for test pieces without strengthening, adding the contribution of fiber reinforcements to the section strength. Fig. 12, indicates the

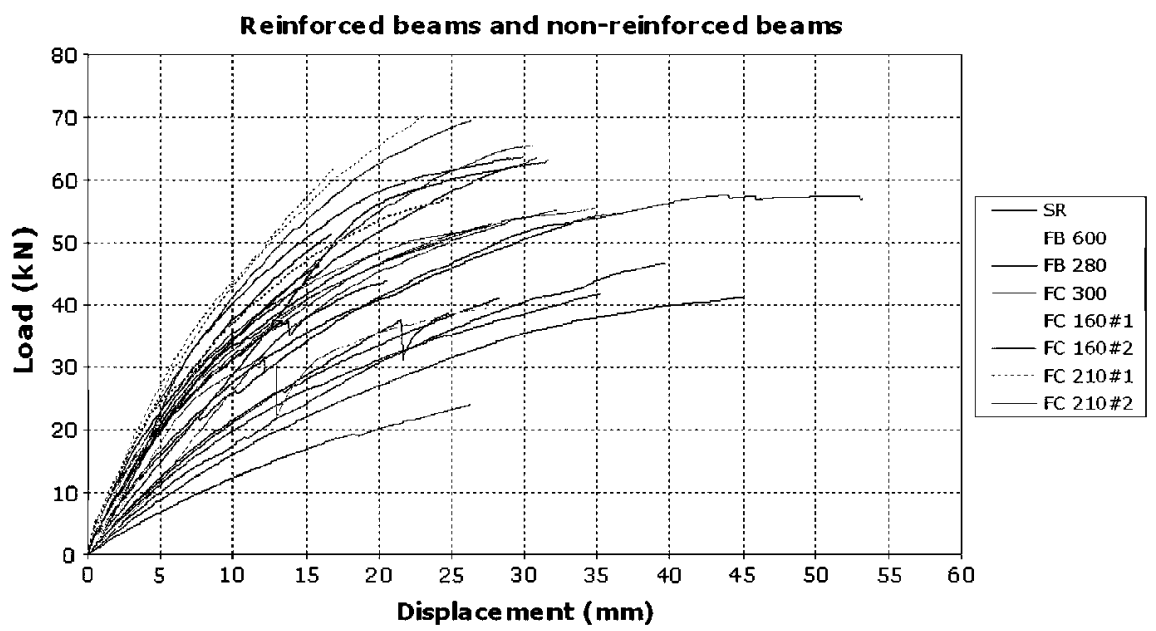

Fig. 8. Load/displacement graph of reinforced beams and non-reinforced beams. 
Table 5

Mean fracture load values of of reinforced and non-reinforced beams.

\begin{tabular}{llll}
\hline Beams & $\begin{array}{l}\text { Mean fracture } \\
\text { load }(\mathrm{kN})\end{array}$ & $\begin{array}{l}\text { Standard } \\
\text { deviation }\end{array}$ & $\begin{array}{l}\text { Variation } \\
\text { coefficient }(\%)\end{array}$ \\
\hline SR & 47.01 & 10.23 & 21.76 \\
FB 280 & 58.55 & 7.30 & 12.47 \\
FB 600 & 54.04 & 1.19 & 2.20 \\
FC 300 & 48.64 & 6.61 & 13.59 \\
FC $160 \# 1$ & 66.35 & 4.07 & 6.13 \\
FC $160 \# 2$ & 67.45 & 1.97 & 2.92 \\
FC 210\#1 & 51.73 & 5.42 & 10.48 \\
FC 210\#2 & 47.54 & 3.00 & 6.31 \\
\hline
\end{tabular}

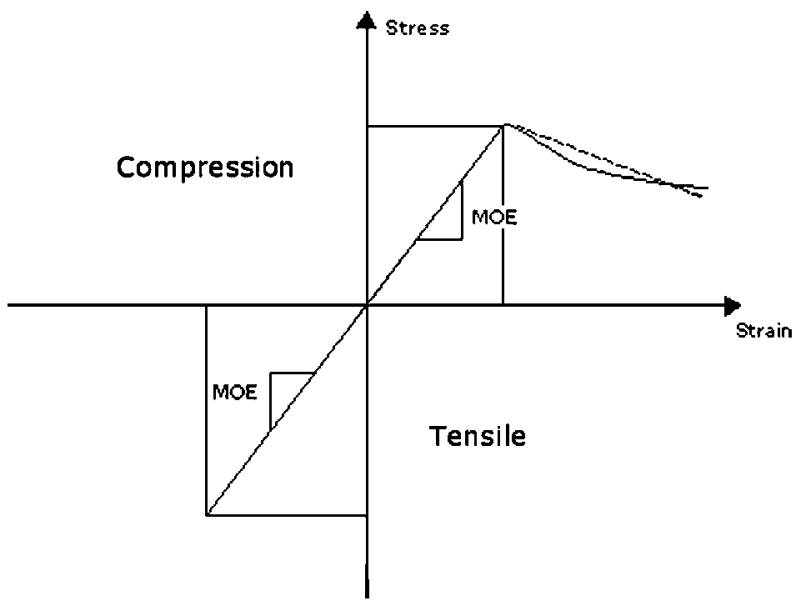

Fig. 9. Stress/strain diagram of timber subjected to tensile stress and compression stress (Buchanan, 1990)

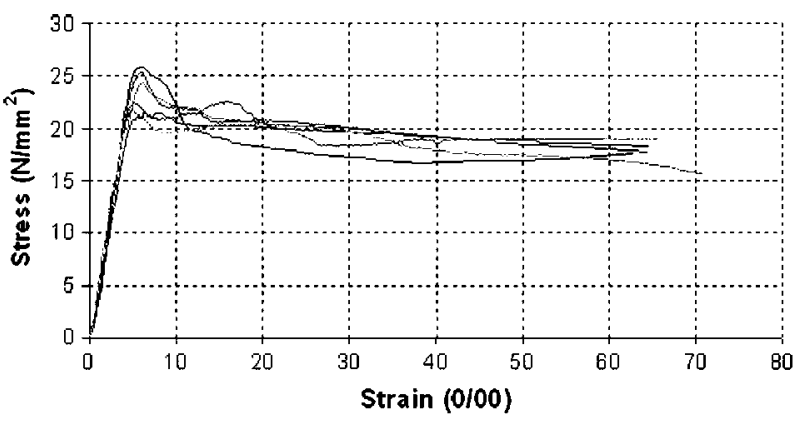

Fig. 10. Stress/strain diagram of parts subjected to compression.

deformation plane (linear) and the wood distribution of stresses (elastoplastic in compression and linear elastic in tension), and that of the reinforcing material (linear elastic in tension and compression). By applying the equilibrium equations (Eqs. (7) and (8)), the equation of compatibility (Eq. (9)), and the laws of behavior (Eqs. (10)-(13)), the moment that balances the section can be obtained to calculate the theoretical load.

Equilibrium equations:

$\sum F=0: \sigma_{w c} \cdot b \cdot y_{c 1}+\frac{1}{2} \cdot \sigma_{w c} \cdot b \cdot y_{c 2}+\frac{1}{2} \cdot \sigma_{r c} \cdot 2 \cdot e_{r} \cdot y_{r c}$

$-\frac{1}{2} \cdot \sigma_{w t} \cdot b \cdot y_{t}-\frac{1}{2} \cdot \sigma_{r t} \cdot 2 \cdot e_{r} \cdot y_{t}-\sigma_{s t} \cdot e_{r} \cdot b=0$

$\sum M=0: \sigma_{w c} \cdot \boldsymbol{b} \cdot y_{c 1} \cdot\left(y_{c 2}+\frac{y_{c 1}}{2}\right)+\frac{1}{2} \cdot \sigma_{w c} \cdot b \cdot y_{c 2} \cdot\left(\frac{2}{3} \cdot y_{c 2}\right)$

$+\frac{1}{2} \cdot \sigma_{r c} \cdot 2 \cdot e_{r} \cdot y_{r c} \cdot\left(\frac{2}{3} \cdot y_{r c}\right)+\frac{1}{2} \cdot \sigma_{w t} \cdot b \cdot y_{t} \cdot\left(\frac{2}{3} \cdot y_{t}\right)$

$+\frac{1}{2} \cdot \sigma_{r t} \cdot 2 \cdot e_{r} \cdot y_{t} \cdot\left(\frac{2}{3} \cdot y_{t}\right)+\sigma_{t t} \cdot e_{r} \cdot b \cdot y_{t}=M_{u}$

Plain sections and strain compatibility: $\frac{\varepsilon_{c 1}}{y_{c 2}}=\frac{\varepsilon_{c 2}}{y_{r c}}=\frac{\varepsilon_{t}}{y_{t}}$

Constitutive laws:

$\sigma_{w c}^{\prime}=E_{w} \cdot \varepsilon_{w}^{\prime} \rightarrow\left(0 \leqslant \varepsilon_{w}^{\prime} \leqslant \varepsilon_{c 1}\right)$

$\sigma_{w c}^{\prime}=\sigma_{w c} \rightarrow\left(\varepsilon_{c 1}<\varepsilon_{w}^{\prime} \leqslant \varepsilon_{c}\right)$

$\sigma_{w t}^{\prime}=E_{w} \cdot \varepsilon_{w}^{\prime} \rightarrow\left(0 \leqslant \varepsilon_{w}^{\prime} \leqslant \varepsilon_{t}\right)$

$\sigma_{r}=E_{r} \cdot \varepsilon_{r}$

where $\sigma_{r c}$ is the maximum compression stress of the reinforcement; $\sigma_{r t}$ is the maximum tensile stress of the reinforcement, and $y_{r c}$ indicates the compression area height of the reinforcement. The value of the elasticity modulus and thickness of $E_{r}$ and $e_{r}$ fibers were taken from datasheets supplied by the supplier and are indicated in Table 1. Table 6 shows the values of ultimate fracture load for each type of reinforcement applied. Experimental loads $\left(F_{\text {exp }}\right)$ correspond to the mean of ultimate load obtained for each reinforcement system. The third column indicates the percentage of ultimate load increase of each reinforcement regarding non-reinforced beams $(\Delta F)$, observing that the best results are obtained with reinforcements $\mathrm{FC} 160 \#$ and FB280, and the worse ones correspond to the reinforcements FC210\#, in one or two layers, and to FC300. The last column shows the coefficients relating the theoretical and experimental loads $\left(F_{\text {exp }} / F_{\text {th }}\right)$. These coefficients show that the theoretical values conform to a greater or lesser extent depending on the type of reinforcement. Cases where greater adjustments are produced are the ones corresponding to reinforcement FC300, FC210\#1 y FC210\#2.

The experimental fracture loads has been smaller than the theoretical one for reinforcements carried out with FC300 and FC210\#2. The highest coefficients correspond to reinforcement type FC160\#1, FC160\#2 and FB280, reaching fracture loads between $18 \%$ and $35 \%$ above the ones expected theoretically. Using Eqs. (7)-(13), and taking the moment experimentally obtained data, maximum tensile stresses reached by the reinforcing fibers have been calculated (Table 7), and the deformation corresponding to this stress also. Table 7 show the values obtained for the wood ultimate tensile stress, the deformation corresponding to that stress $(\varepsilon)$ and the maximum stress reached by the reinforcing fibers $\left(\sigma_{\mathrm{rt}}\right)$.-The last column indicates the stress achieved by each reinforcement, in percentage, in relation to its tensile strength. They are, in general, larger percentages in the reinforcements made of carbon fibers, however, the mean ultimate fracture load obtained on the beams reinforced with FB280 is higher to that obtained with the reinforcement FC300, FC210\#1 and FC210\#2.

\section{Results analysis}

Comparing the basalt fiber reinforcements performed, it can be observed that beams reinforced with FB280 reach an ultimate fracture load and an ultimate fracture stress in the reinforcement exceeding the ones reinforced with FB600. The mean ultimate

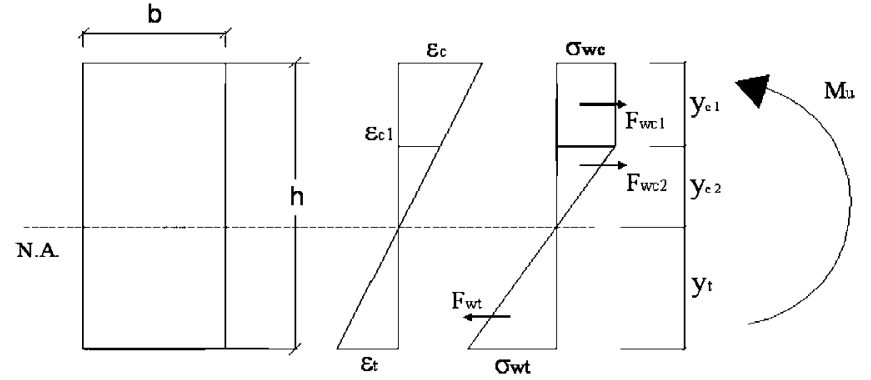

Fig. 11. Beam section equilibrium without reinforcement. 


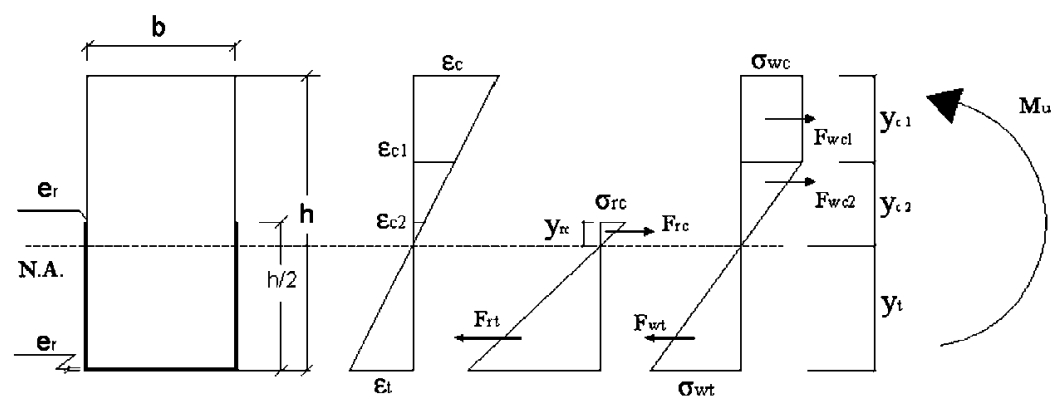

Fig. 12. Reinforced beam section equilibrium.

Table 6

Mean fracture load values, theoreticals and experimentals.

\begin{tabular}{lllll}
\hline Reinforcement type & $F_{\text {exp }}(\mathrm{kN})$ & $\Delta F^{\mathrm{a}}(\%)$ & $F_{\mathrm{th}}(\mathrm{kN})$ & $F_{\mathrm{exp}} / F_{\mathrm{th}}$ \\
\hline SR & 47.01 & - & - & - \\
FB 280 & 58.55 & 24,55 & 49.68 & 1.18 \\
FB 600 & 54.04 & 14,95 & 49.85 & 1.08 \\
FC 300 & 48.64 & 3,47 & 50.50 & 0.96 \\
FC 160\#1 & 66.35 & 41,14 & 49.68 & 1.34 \\
FC 160\#2 & 67.45 & 43,48 & 49.84 & 1.35 \\
FC 210\#1 & 51.73 & 10,04 & 49.77 & 1.04 \\
FC 210\#2 & 47.54 & 1,13 & 50.10 & 0.95 \\
\hline
\end{tabular}

${ }^{a}$ Is the percentage of ultimate load increase of each reinforcement regarding non-reinforced beams.

Table 7

Values of maximum stress and strain of the reinforcement fibers.

\begin{tabular}{llrcl}
\hline $\begin{array}{l}\text { Reinforcement } \\
\text { type }\end{array}$ & $\begin{array}{l}\sigma_{\operatorname{maxw}}(\mathrm{N} / \\
\left.\mathrm{mm}^{2}\right)\end{array}$ & $\varepsilon(\%)$ & $\begin{array}{l}\sigma_{\operatorname{maxFP}}(\mathrm{N} / \\
\left.\mathrm{mm}^{2}\right)\end{array}$ & $\begin{array}{l}\sigma_{\operatorname{maxFRP}} / f_{\mathrm{FRP}} \\
(\%)\end{array}$ \\
\hline FB 280 & 52.43 & 10.49 & 881.08 & 22.03 \\
FB 600 & 42.92 & 8.18 & 687.54 & 17.19 \\
FC 300 & 29.05 & 5.81 & 1336.57 & 27.28 \\
FC 160\#1 & 56.60 & 11.32 & 2604.12 & 53.15 \\
FC 160\#2 & 47.20 & 9.44 & 2171.63 & 44.32 \\
FC 210\#1 & 42.05 & 8.41 & 1934.69 & 39.48 \\
FC 210\#2 & 32.00 & 6.40 & 1472.29 & 30.05 \\
\hline
\end{tabular}

stress of the $\mathrm{FB} 280$ is $20 \%$ of its strength, while the FB600 is almost $16 \%$.

Comparing the three unidirectional fabrics, best results were obtained with FB280, followed by FB600 and finally FC300, while the ultimate stress of FC 300 was higher than that of FB280 and FC210. However, the strain corresponding to the ultimate stress was greater in basalt fiber reinforcements. Of the three types of carbon fiber reinforcement, the one made with bi-directional FC160\# carbon fiber fabric offers better results than the unidirectional FC300. The mean value of the fracture load of the beams reinforced with FC160\#1 is a $36 \%$ higher than those reinforced with FC300, even though the grammage is nearly half that of the other case. The maximum strength reached by the FC160\# is greater than that of the FC210\#, i.e. there is a greater use of the mechanical properties of the fibers in the case of the FC160\#. No big differences are observed between the ultimate load obtained with reinforcements FC160\# and FC210\# placed in one or in two layers respectively.

FC160\#2 reinforcement obtained the greatest increase of fracture load in relation to the non-reinforced beams. The same reinforcement with a single layer of fabric FC160\#1 reached similar results.

Knowledge of new reinforcement techniques applied to traditionally used materials such as the wood has aspects of great interest. This article experimentally proves the proper functioning of basalt and unidirectional carbon FRP and that of bi-directional carbon fiber fabric systems glued externally with epoxy resins to sawn timber pine beams.

The results analysis of Fig. 8 indicates that reinforcement systems studied in this work are effective to increase the initial performance of beams without reinforcement. Reinforced beams reach higher fracture loads and their rigidity is increased regarding the sample pieces without reinforcement. However, the experienced ultimate displacement is not increased in the reinforced specimens.

The application of two reinforcement layers did not imply an increase in the carrying capacity of the beams (Table 4 and Fig. 7) with respect to beams reinforced with only a single layer. Beams reinforced with two layers of carbon fiber bi-directional fabrics offer virtually the same strength as the beams reinforced with a single layer.

Comparing the basalt fiber reinforcements performed, it can be observed that beams reinforced with FB280 reach an ultimate fracture load and a maximum stress in the reinforcement exceeding the ones reinforced with FB600. The mean ultimate stress of the FB280 is $22 \%$ of its strength, while the FB600 is $17 \%$.

Comparing the three unidirectional fabrics, best results were obtained with FB280, followed by FB600 and finally FC300 (Table 6), while the ultimate stress of FC 300 was higher than that of FB280 and FB600. However, the strain corresponding to the ultimate stress was greater in basalt fiber reinforcements (Table 7).

Of the three types of carbon fiber reinforcement, the one made with bi-directional FC160\# carbon fiber fabric offers better results than the unidirectional $\mathrm{FC} 300$. The mean value of the fracture load of the beams reinforced with FC160\#1 is a $36 \%$ higher than those reinforced with $\mathrm{FC} 300$, even though the grammage is nearly half that of the other case (Table 6 ). The maximum stress reached by the $\mathrm{FC160 \#} \mathrm{is} \mathrm{greater} \mathrm{than} \mathrm{that} \mathrm{of} \mathrm{the} \mathrm{FC210 \# ,} \mathrm{i.e.} \mathrm{there} \mathrm{is} \mathrm{a} \mathrm{greater} \mathrm{use}$ of the mechanical properties of the fibers in the case of the FC160\#. FC160\#2 reinforcement obtained the greatest increase of fracture load in relation to the non-reinforced beams. The same reinforcement with a single layer of fabric FC160\#1 reached similar results.

Stiffness increases with the tissues grammage, however, the increase of the carrying capacity is greater in beams reinforced with less grammage fabrics (FC160\#) and in those with basalt fiber fabrics (FB280), being in these cases, the most significant deformation at the fracture moment.

The calculation model used for analyzing reinforced beams has given very good results in all cases, except for the beams reinforced with bi-directional carbon fiber tissues of $160 \mathrm{~g} / \mathrm{m}^{2}$, where the model predicts lower fracture load than those actually achieved (Table 6).

As can be seen in Table 7 , reinforcement works well below its potential. The basalt fiber ultimate deformation is a $50 \%$, and that of carbon fiber $21 \%$. However, ultimate deformations calculated just reach $11.32 \%$ (carbon fiber) and $10,49 \%$ (basalt fiber), which 
represents a $54 \%$ and $21 \%$ of the fracture values for carbon and basalt fibers respectively. The use of carbon fiber is optimized as opposed to basalt fiber, due to its higher elasticity modulus (almost three times as much). Tensile fracture of reinforced beams occurs due to tensile wood failure when reaching ultimate tensile stress deformation. At that moment, the stress reached by the reinforcements is obtained as the product of the ultimate tensile strain of wood and the elasticity modulus of the fabrics. The bigger the elasticity modulus of the fabric, the greater the stress developed at the failure moment.

\section{Conclusions}

Reinforcement systems of wooden pine beams with basalt and carbon FRP glued at the exterior give rise to structures with greater stiffness and carrying capacity than the initial ones. However, the ultimate displacement experienced is not increased in the reinforced beams.

The ultimate load of beams reinforced with two layers of bidirectional carbon fiber fabric is very similar to the ultimate load of beams reinforced with a single layer.

The fracture load of beams reinforced with FB280 is higher than the fracture load of beams reinforced with FB600. The mean maximum stress of the FB280 is $22 \%$ of its strength, while that of FB 600 is $17 \%$.

Results obtained with unidirectional reinforcements performed with basalt fiber are higher than those obtained with carbon fiber, which implies a great economic interest due to the much lower price of basalt fabric when compared to the price of carbon fabric.

The use of bi-directional fabrics offers better results than unidirectional fabrics, even when the bi-directional fabrics are used in lower grammages than unidirectional ones.

In the case of bi-directional carbon fiber tissues, the use of two reinforcement layers shows a minor optimization of the reinforcing material.

The beam stiffness increases as the grammage of the fabrics increases.

The strength analytical study of reinforced beams considering a elastoplastic behavior for wood in compression and a linear elastic behavior for wood in tension and the reinforcements, have given very good results in all cases, except on the beams reinforced with bi-directional carbon fiber fabrics of $160 \mathrm{~g} / \mathrm{m}^{2}$, where the model predicts fracture loads lower than those actually achieved.

The ultimate tensile strain of the reinforcement is very high ( $50 \%$ for carbon fiber and $21 \%$ for basalt fiber), which prevents the maximum stress of these materials to be reached.

Tensile fracture occurs due to the facture of the wooden fibers when reaching the ultimate tensile deformation, much lower than that of reinforcement materials.

In terms of stresses, carbon fiber use is better optimized, rather than basalt fiber due to its higher elasticity modulus.

\section{Acknowledgments}

The authors thank the School of Building Engineering of the Polytechnic University of Madrid, for financing this work. Also, the support of Drizoro Construction Products, S.A.U. is gratefully acknowledged.

\section{References}

[1] González Bravo C. Recuperación de la capacidad mecănica en piezas de madera solicitadas a flexión en estructuras tradicionales operando por la cara superior mediante refuerzos y prôtesis metálicas. PhD Thesis. E.T.S. of Architecture, Polytechnic University of Madrid, Spain, 2007.

[2] Buchanan AH. Bending strength of lumber. ASCE J Struct Eng 1990;3:391-7.

[3] Theakston F H. A feasibility study for strengthening timber beams with fibreglass. Can Agric Eng 1965:17-9.

[4] Biblis EJ. Analysis of wood-fiberglass composite beams within and beyond the elastic region. For Prod J 1965;15:81-8.

[5] Spaun FD. Reinforcement of wood with fibreglass. For Prod J $1981 ; 31(4): 26-33$

[6] Plavris N, Trintafillou TC. FRP Reinforced wood as structural material. J Mater Civ Eng 1992;4(3):300-15.

[7] Triantafillou T, Deskivic N. Prestressed FRP sheets as external reinforcement of wood members. ASCE J Struct Eng 1992;118(5):1270-84.

[8] Brunner M. Theoretical strength limits of timber beams fortified with prestressed artificial fibres. In: Proceedings of WCTE, August 2002. Malaysia.

[9] Brunner M, Schnueriger M. Timber beams strengthened with prestressed fibres: Delamination. In: Proceedings of WCTE, June 2004. Finland.

[10] Abdel-Magid B, Scholsky K, Shaler S, Dagher H, Kimball T. Interfacial bonding between phenolic matrix composites and wood. In: Proceedings of ICCI, January 1996:67. Arizona.

[11] Sonti SS, Ganga Rao HV. Strength and stiffness evaluations of wood laminates with composite wraps. In: Proceedings of 50th Annual Conference, Composites Institute. SPI, 1995.

[12] Dhager $\mathrm{HJ}$. Performance wood composite for construction. In: Proceedings of EBRAMEM, Brasil, 2000.

[13] Schober K U, Rauntenstrauch K. Experimental investigation on flexural strengthening of timber structures with CFRP. In: Proceedings of international symposium on bond behaviour of FRP in Structures, 2005.

[14] Greenland A, Crews K, Bakoss S. Application of advanced fibre composite reinforcements to structural timber. In: Proceedings of pacific timber engineering conference. New Zealand, March, 1999, p. 93.

[15] Triantafillou T. Shear reinforcement of wood using FRP materials. ASCE J Mater Civ Eng 1997;9(2):65-9.

[16] Radford DW, Van Goethem D, Gutkowski RM, Peterson ML. Composite repair of timber structures. Constr Build Mater 2002;16:417-25.

[17] Gentile C, Svecova D, Saltzberg W, Rizkalla S H. Flexural strengthening of timber beams using GFRP. In: Proceedings of Advanced Composite Materials in Bridges and Structures, August 2000:637-44. Canda.

[18] Hallstrom S, Grenestedt JL. Failure analysis of laminated timber beams reinforced with glass fiber composites. Wood Sci Technol 1997;31:17-34.

[19] Johns KC, Lacroix S. Composite reinforcement of timber in bending. Can J Civ Eng 2000;27:899-906.

[20] Pavez A, Ansell MP, Smedley D. Mechanical repair of timber beams fractured in flexure using bonded-in reinforcements. J Compos: Part B 2009:40(2):95-106.

[21] Borri A, Corradi M, Grazini A. FRP reinforcement of wood element under bending loads. In: Proceedings of structural faults and repair, July 2003. Londres.

[22] Borri A, Carrodi M, Grazini A. A method for flexural reinforced of old wood beams with CFRP materials. J Compos: Part B 2005;36(2):143-53.

[23] Bla $\beta$ H J, Romani M. Design model for FRP reinforced glulam beams. In: International council for research and innovation in building and construction, working commission W18- timber structures 2001 . Meeting 34 , Venice, Italy.

[24] Carmisciano S, De Rosa IM, Sarasini F, Tamburrano A, Valente M. Basalt woven fiber reinforced vinylester composites: flexural and electrical proprieties. Mater Des 2011;32:337-42.

[25] Haojun W, Yuye H. Experimental study on flexural behaviour of timber beams reinforced with FRP sheets. Ind Constr 2010:4.

[26] Kuilen J. Theorical and experimental research on glass fiber reinforced laminated timber beams. In: Proceedings of international timber engineering conference. September, 1991, London.

[27] Lindergerg R F. A nonlinear stochastic model for the analysis of reinforced glulam beams in bending. In: $\mathrm{PhD}$. dissertation, Department of Civil and Enviromental Engineering, Univerity of Maine, Ocono, ME, 2000.

[28] Blaß H J, Romani M. Load-bearing capacity and strain behaviour of FRP reinforced glulam composite beams. Research report: Schluss bericht AiFVarhaben $11407 / \mathrm{N}$, Karlsruhe, 2000.

[29] Dorey A, Cleng J J. The behaviour of GFRP glued laminated timber beams. In: Proceedings of international conference of advanced composite materials in bridges and structures. Montreal, August 1996, p. 787-94

[30] Belperio P, Grad I E. The performance of glulam beams reinforced with carbon fiber. In: Proceedings of pacific timber engineering conference, New Zealand, 1999, p. 99-06.

[31] Tingley D, Kent S. Structural evaluation of fiber reinforced hollow wood beams. In: Proceedings of international conference of advanced composite materials in bridges and structures. Malta, September 2001, p. 367-72.

[32] Fiorelli J, Alves A. Analysis of the strength and stiffness of timber beams reinforced with carbon fiber and glass fiber. Mater Res 2002;6(2):193-202.

[33] Yus of A, Saleh AL. Flexural strengthening of timber beams using glass fiber reinforced polymer. Electron J Struct Eng 2010;10:45-56. 